\title{
AUTOMATION OF INCINERATION PLANT DEMOLITION AND UTILIZATION OF INFORMATION TECHNOLOGY
}

\author{
Takuya Gokyuu* ,Mitsuo Niihara**, Toshiji Kanai**, \\ Shouji Gotou**, Youichi Aoki*** Kazunori Shibano**** \\ *Institute of Technology ,Tokyu Construction Co.,Ltd.3062-1 Tana, Sagamihara-city, Kanagawa, JAPAN \\ **Civil Works SUB-Div.,Metropolitan Div.,Tokyu Construction Co.,Ltd. shibuya1-16-4,shibuya-ku,Tokyo,JAPAN \\ ***Solution Business Div.,Tokyu Construction Co.,Ltd. shibuya1-16-14,shibuya-ku,Tokyo,JAPAN \\ ****Civil Engineering Div.,Tokyu Construction Co.,Ltd. shibuya1-16-14,shibuya-ku,Tokyo,JAPAN
}

\begin{abstract}
:
In 1999," Law Concerning Special Measures against Dioxins” was enacted. An incineration plant exceeding the effluent standard of dioxins stops operation and the plan of demolition is carried out. When demolish an incineration plant polluted by dioxins , it is necessary to ensure worker' s safety, neighbor' s health and their living environment. Authors have developed an automatic equipment which removes ash containing dioxins inside of the chimney pipe of an incineration plant with high-pressured water. This equipment could be operated by remote control and set workers free from heavy work at high and narrow space in a chimney pipe. Moreover, exact removal of ash is possible by automatic control. An opening and closing type of tent for environmental safety and an information system which provides scenes of site works, revel of noise and vibration, particle counts and process of discharging toxic wastes to neighbors are also made up. This paper reports an automation of a chimney demolition and a case of risk communication with information disclosure.
\end{abstract}

Keywords: Dismantlement, Incineration Plant, Toxic Waste, Removal, Risk Communication

\section{Introduction}

In 2001, "Guidelines for avoiding the exposure to dioxins during work at waste incineration plant" was enacted as to demolition of an incineration plant contaminated with dioxins. The guidelines dictate that demolition of such a plant be carried out by protecting workers as well as adjacent areas against exposure to dioxins.

Demolition workers have to wear such gears as protective clothing and mask to prevent themselves from being exposed to dioxins, resulting in poor workability. Since they usually work in elevated and/or confined spaces, it is eagerly expected to develop the safe and highly efficient techniques that would be feasible at cost comparable to that for conventional techniques. The new techniques should be used to mechanize and automate the work. It is also expected to develop an on-site environment control system that will not cause an adverse impact on environment of areas surrounding the demolition site.

We have developed a "Chimney inner wall flushing tool (see Figure 1)" that can automatically remove accumulated pollutants. This tool has been used in demolition work of the incineration plant and in this paper this application of the tool to those assignments is set forth together with the description of our proprietary

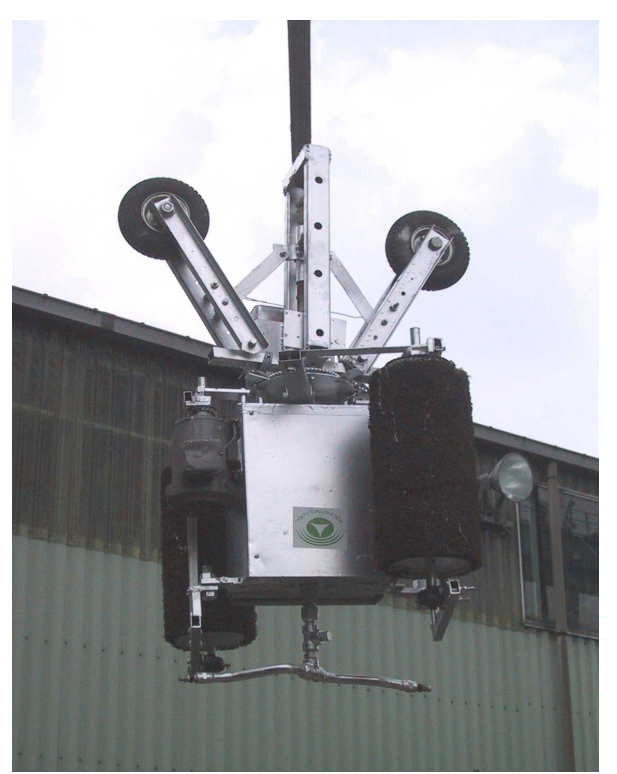

Figure 1 Chimney Inner Wall Flushing Tool "environment control system". 


\section{Concepts}

Against the backdrop such as above situation, we have developed the tool with the following concepts in mind:

(1) To automate work for dismantling the chimney at the incineration plant where it is highly possible that the personnel are exposed to dioxins.

(2) To make the tool compact and lightweight and to make the ancillary facility smaller in size.

(3) To improve the quality of work through uniform pattern of operation.

(4) To control environment of the site to secure health and living conditions of people in the vicinity.

\section{Chimney Inner Wall Flushing Tool}

\subsection{Outline of Flushing Tool}

At the site where traditional practice is followed, a worker who wears such protective gears (see Figure 2) is suspended in the gondola down into the chimney and then manually flushes the wall. According to other conventional method, an automatic injection nozzle rotating under pressure is also suspended down into the chimney.

These conventional techniques have problems as follows: In the former case of manual flushing, the worker is placed under hash working conditions where he has to wear the protective gears in narrow space. In the latter case of automatic flushing, the nozzle movement pattern is empirically controlled. The new flushing tool has been introduced to remove stuck pollutants that include such toxic substances as dioxins from the inside wall surface of an inner pipe, inner diameter of which is about $1 \mathrm{~m}$.

This tool is composed of three units (see Figure 3), a "rotary flushing nozzles", a "rotary brush units" and a "reaction force unit (guide rollers)."

The rotary flushing nozzle rotates and sprays high-pressure water to flush the wall. The rotary brush unit whirls round inside of the inner pipe while pressing the rotating brush against its inner wall. The reaction force unit holds the tool itself on the inner wall while creating a whirling reaction force from the brush. When the inner wall is not of steel but protected with fire bricks or sprayed with heat insulator, it is possible to dismount the rotary brush unit from the tool and to flush the wall.

\subsection{Features of Flushing Tool}

The tool that flushes the inner wall of an inner pipe in the chimney has been put to practical use so as to translate the foregoing concepts into reality.

The tool has the following features:

(1) Highly effective flushing capability attained by combination of water feed under high pressure and scrubbing on the wall with the rotating brush.

(2) Since the root of the rotating high-pressure rotating nozzle is held at the axial center of the pipe by the reaction force unit (a guide roller), the distance between the nozzle

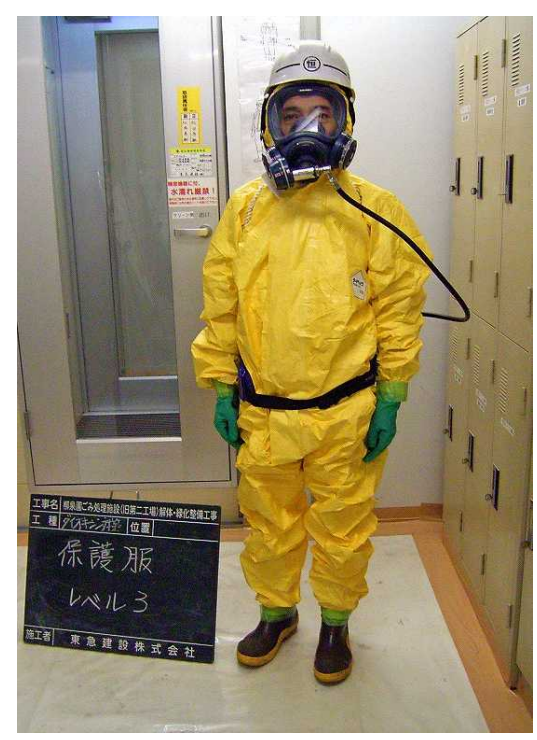

Figure 2 Protective Clothing and Protective Gears

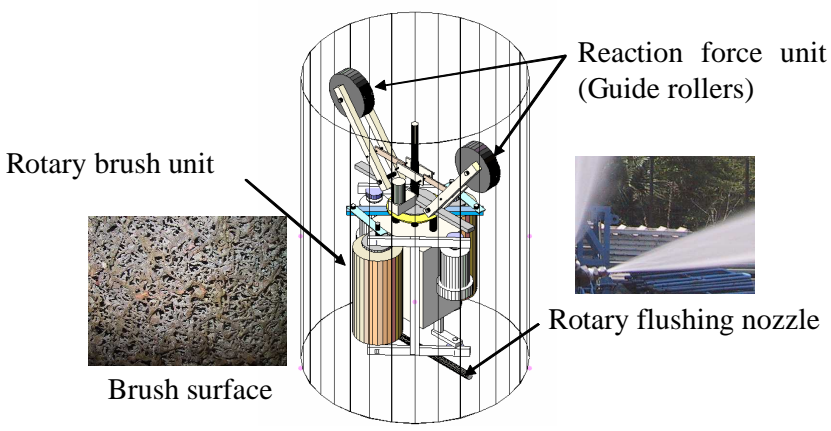

Figure 3 Components of Flushing Tool

and the wall can be kept constant, resulting in uniform wall flushing.

(3) Movement and flushing pattern of the flushing tool are optimized under control of a controller.

(4) Versatile application of the tool is achieved by arbitrarily setting up the nozzle rotation speed for the target wall. The technology used in the attachment (the flushing unit) ${ }^{[1]}$ for the wall-surface operation robot is applied to this flushing technique.

(5) The rotating brush is made of the "abrasive particle impregnated nylon non-woven fabric" that has proven excellent in base metal preparation for painting practices2). It is pressed against the wall by the force of high-pressure water. This may be one of the methods that make effective use of energy derived from high-pressure water. 


\subsection{Flushing Tool Specifications}

The flushing tool specifications are listed in Table 1. An electric motor is used to rotate the flushing nozzle, the brush and the brush unit. The injection nozzle is subject to the high pressure water spray test (Figure 4) to check for proper relations between the water flow rate and the pressure as well as the injection pattern. The tip attached on the injection nozzle is commercially available; there are a variety of combinations of injection angle and injection hole size. Thus, the one which is considered most effective for the specific conditions of pollutants accumulated on the wall has been selected. The nozzle withstands an injection pressure of up to $25 \mathrm{Mpa}$.

Table 1 Flushing Tool Specifications

\begin{tabular}{l|l}
\hline Item & Specifications \\
\hline Dimensions & $685(\mathrm{~L}) \times 685(\mathrm{~W}) \times 1,500 \mathrm{~mm}(\mathrm{H})$ \\
\hline Mass & $100 \mathrm{~kg}$ \\
\hline Applicable diameter & $\Phi 850$ to $1,200 \mathrm{~mm}$ \\
\hline Nozzle rotation speed & $30 \mathrm{rpm}($ Normal $)$ \\
\hline Brush rotation speed & $700 \mathrm{rpm}($ Normal) \\
\hline Brush whirling speed & $1.87 \mathrm{rpm}($ Normal $)$ \\
\hline Maximum spray pressure & $25 \mathrm{MPa}$ \\
\hline Spray rate & $20 \mathrm{l} / \mathrm{min}($ depending on pump performance) \\
\hline
\end{tabular}

\subsection{System Construction}

A typical flushing system using the flushing tool is illustrated in Figure 5. The control box and the winch are installed atop the chimney, while the power and the high-pressure water are supplied from the ground. Connected to the flushing tool are a high-pressure water hose, a control cable, a hoist wire, and a positional measurement wire. Equipment located atop the chimney can be placed on the ground. Drain is collected at the bottom of the chimney and pumped out to the effluent treatment facility. The dust collector with the HEPA filter is installed in order to keep the pressure in the work area around the chimney lower than the surroundings.

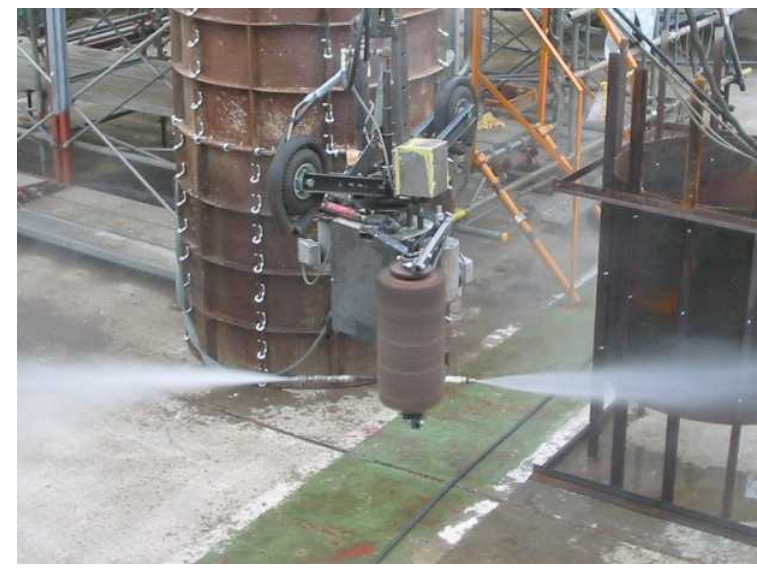

Figure 4 High-Pressure Water Injection Test

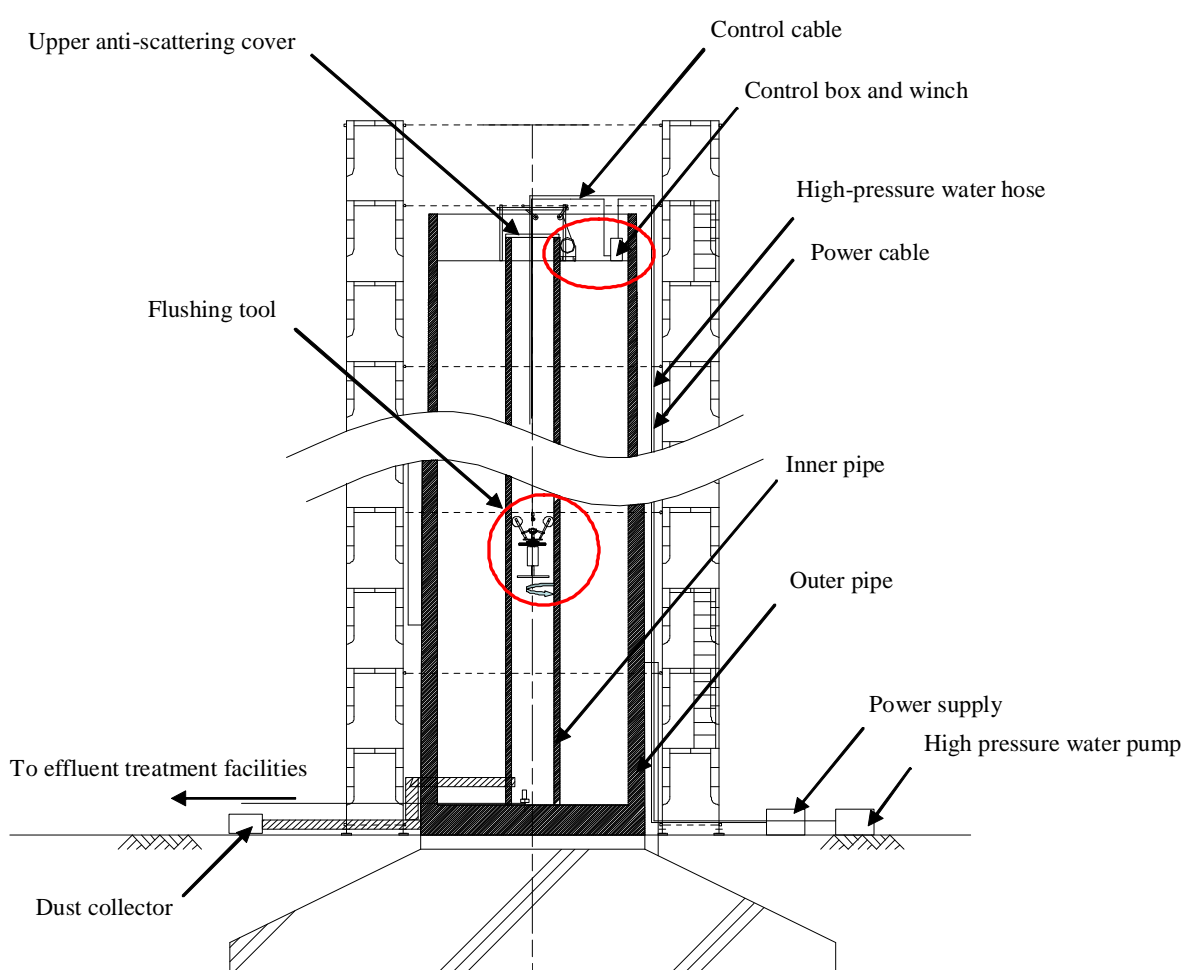

Figure5 Typical Flushing System 


\section{Envir onment Control System}

It is essential that the demolition businesses establish the environment control system and offer the opportunity of information disclosure in order to develop a relationship of trust between the businesses and the local residents. In the present case, we plan to come up with the following information disclosure and environment control scheme to keep the residents posted about the safety control status (Figure 6):

(1) Disclosure of visual information on the work (the work monitoring system).

(2) Disclosure of real-time data on the surrounding environment (Dust concentration monitoring system).

(3) Traffic control and other information disclosure about the disposal of specially controlled industrial waste that includes dioxins (Traffic control system of waste carrying vehicles is established with the aid of the GPS system.).

(4) Control of vibrations and noise (Vibration and noise monitoring system).

\subsection{Work Monitoring system}

The work monitoring system uses a network of cameras that cover the progress of demolition work. Each camera is panned and tilted, while the site is zoomed in on or out, on the PC screen. Thus, we are now capable of watching operators who are working in hard-to-access locations where harmful substances, such as dioxins, prevail or of keeping track of heavy machinery being operated at the site.

\subsection{Dust Concentration Monitoring system}

During the removal of such toxic substances as dioxins, the dust concentration monitoring system presents the dataon dust that may be scattered from the building under demolition. Collected at four points around the site, the data also includes real-time wind direction and velocity measurements.

A dust meter can measure the amount of airborne particles, such as pollen and yellow sand, as well as rainfall that are generated from other sources than the demolition work site. The SPM (Suspended Particulate Matter) meter is concurrently installed with the dust meter at one of these four points. Data acquired from this SPM meter is compared with official one from the SPM meter that is installed by the municipality. Through this comparison, it is possible to determine if scattered dust is originated in the demolition work or not. The dust control method has thus been clearly defined.

\subsection{Traffic Control System of Waste Disposal Vehicle}

Since an illegal dumping of industrial waste constitutes one of serious social issues, it is important to assure that the industrial waste is properly delivered to the waste treatment plant. The traffic control system monitors in real time the traffic condition of the vehicles hauling waste from the demolition site to the plant. Dependent on the GPS system operated by a third party (i.e., NPO), the system discloses the traffic information on the vehicles to the local people. An

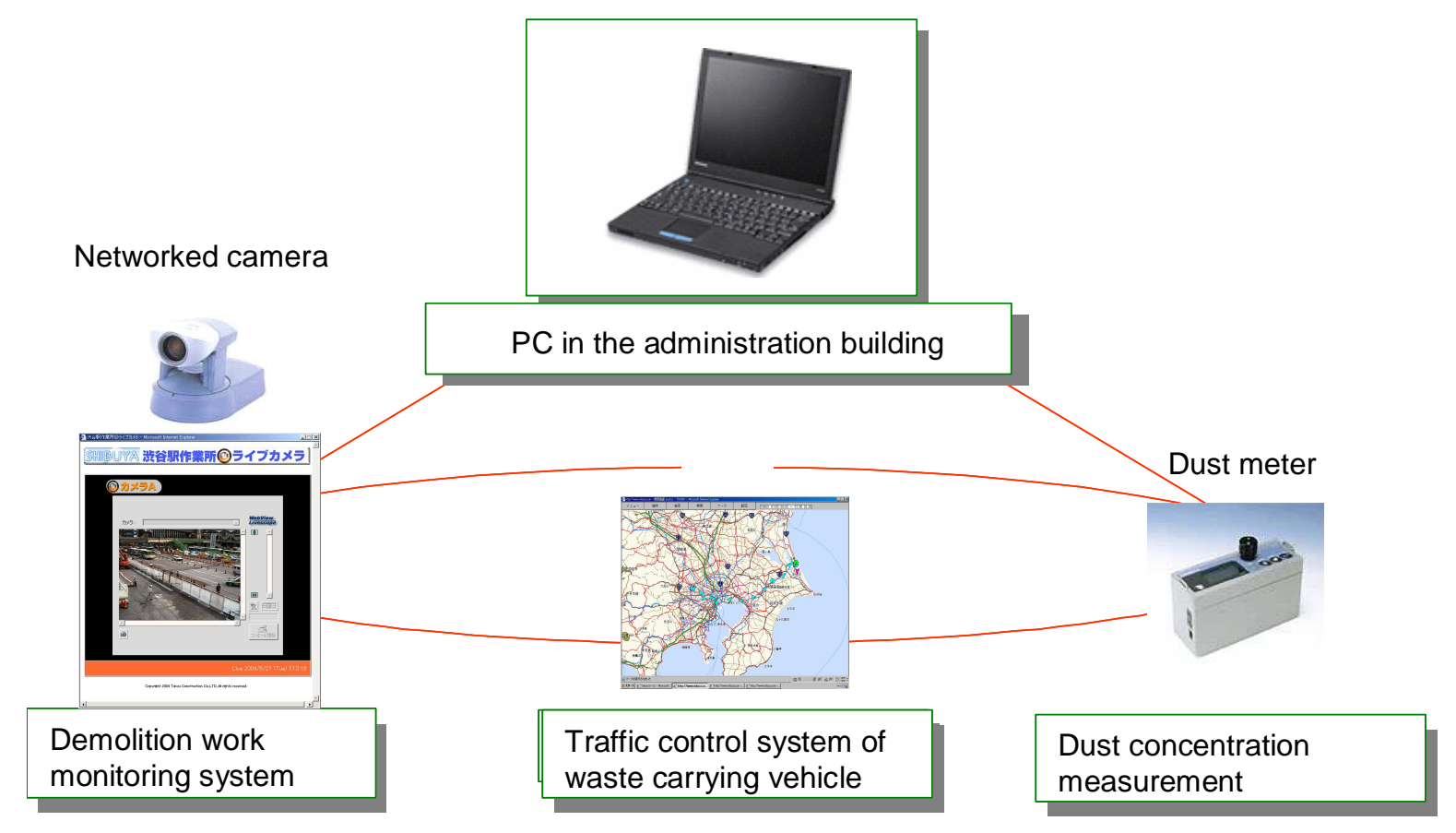

Figure 6 Environment Control System 
IC tag is attached to the waste discharged from the point of source so that the course of its travel is traced until it reaches the destination. All the information about the waste (such as the kind and amount) could also be disseminated in real time via the Internet.

\subsection{Vibration and Noise Monitoring system}

Heavy vibrations and loud noise are likely to develop at the site where a building is pulled down. The vibration and noise monitoring system displays such data in real time, conducts reduction of the measurements, and outputs the report.

\section{Example of Work}

\subsection{Outline of Work}

We have used this system and equipment in the demolition work of the waste disposal facilities (Figure 7) whose processing capacity is $240 \mathrm{t} / \mathrm{day}$. This work included the demolition of processing plant, incineration facility, exhaust gas treatment facility, ash handling facility, chimney $(59 \mathrm{~m})$ and other facilities.

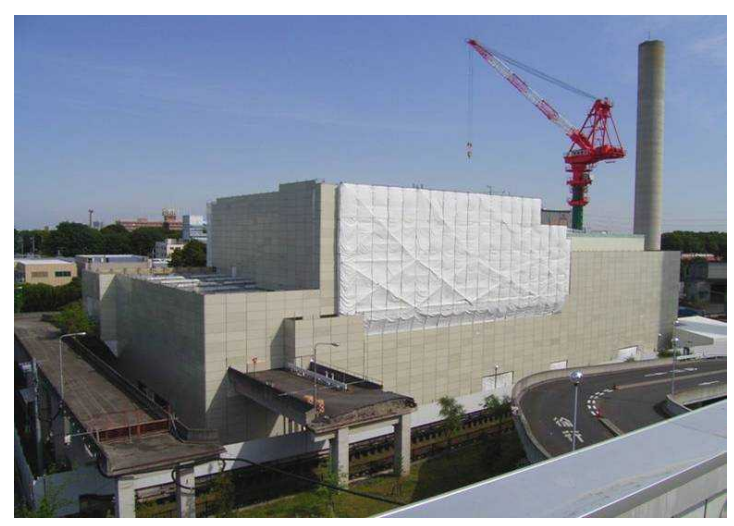

Figure 7 View of Demolition Site

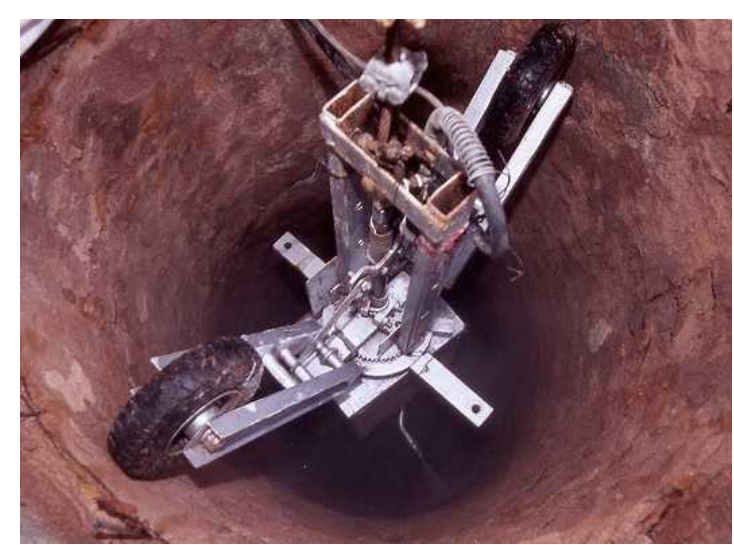

Figure 8 Flushing Tool in Chimney

\subsection{Removal of Accumulations with Flushing Tool}

Using the flushing tool, pollutant accumulations were removed from areas from the top of the inner pipe wall coated with fireproof material to the flue connection over the entire length of $52 \mathrm{~m}$ (see Figure 8). The entire surface of the inner wall had to be flushed completely. In the present case, the flushing pattern was designed such that the spray width $(100 \mathrm{~mm})$ of the high-pressure water would overlap each other by $50 \mathrm{~mm}$ as illustrated in Figure 9. In this pattern, the tool descended by $50 \mathrm{~mm}$ per second and then it was held at each position for four seconds, during which the nozzle was rotated and the wall surface was flushed. In other words, the tool descended $50 \mathrm{~mm}$ in 5 seconds to flush the surface, meaning that its descending speed was $0.6 \mathrm{~m} / \mathrm{min}$. Therefore, in theory, it would take 87 minutes to flush the wall $52 \mathrm{~m}$ long. However, the actual period of time required to complete the flushing was 100 minutes that was about $15 \%$ longer than calculated. This is because, in the course of the flushing work, additional tasks, such as securing the high-pressure water hose with the wire, were required. In terms of efficiency in area per hour, the actual efficiency was $93 \mathrm{~m}^{2} /$ hour, which is obtained by dividing the total area of $155 \mathrm{~m}^{2}$ by the period of time required (100 minutes).

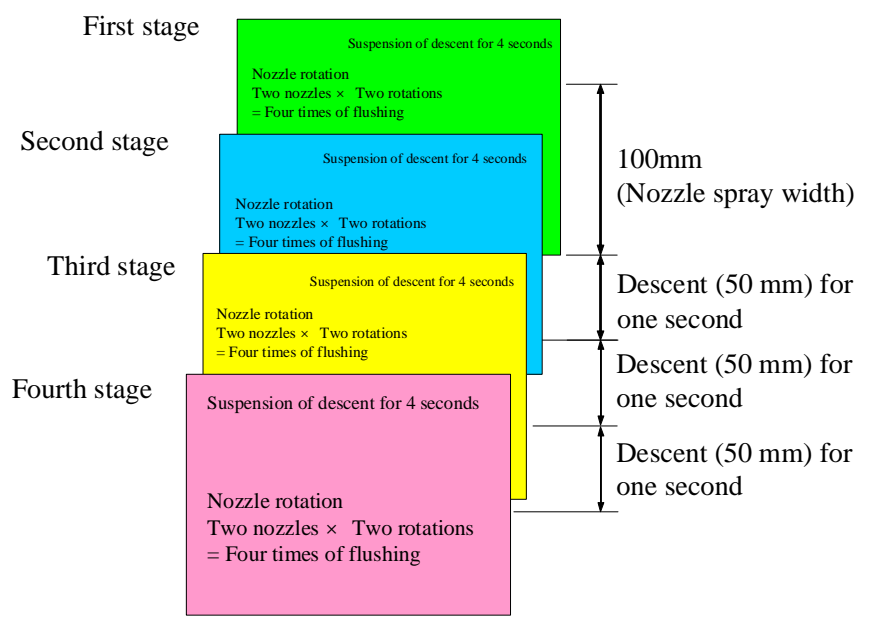

Deployed View of Inner Wall of Inner Pipe

Figure 9 Flushing Pattern 


\subsection{Environment Control System}

Information on the environment was disclosed to the people living near the demolition site via the PC (see Figure 10) installed in the administration building adjacent to the incineration plant in operation. The disclosed information included the video image of demolition work, dust meter readings, and the position of waste hauling vehicles. Vibration and noise data was shown on the display located at the site.

\subsection{Effectiveness of Introduced Flushing Tool}

After removal of pollutant accumulations from the inside of the inner pipe, the work was continued at the site that was graded to be the first level of the control area (i.e., an area at the protection level 1). A comparative study conducted on inner wall conditions before and after removal of accumulations revealed that pollutants are flushed away from the surface as expected. In addition, since the tool is relatively small in size and lightweight, the turning task between two inner pipes was found to be simple.

Information from the on-site environment control system allowed the people in the neighborhood to understand that we were carrying out demolition and disposal of the waste properly according to the plan.

\section{Conclusions}

We have to give special consideration to the environment in the work place and surrounding areas since we handle toxic substances, while tearing down the incineration plant.

The chimney inner wall flushing tool we have developed is expected to release workers from the job in a hazardous environment while in a given portion of the work process. As a result of introducing the environment control system as well as active information disclosure practice, the demolition work progressed smoothly.

We intend to proceed with mechanization and automation of the system and with development of the measurement system, which would support the safe and high quality construction projects at reasonably reduced cost, since the mechanization and automation of work, environment control, and risk communication is supposed to be essential in construction and demolition undertakings regardless of whether or not handling of harmful substances is involved.

\section{References}

[1] Takuya Gokyuu, Junichi Matsunaga and Ken Endo, "Application of Wall-Surface Operation Robot to Coal Silo Repairs", Eighth Symposium on Construction Robotics, July 2000, pp. 295-302

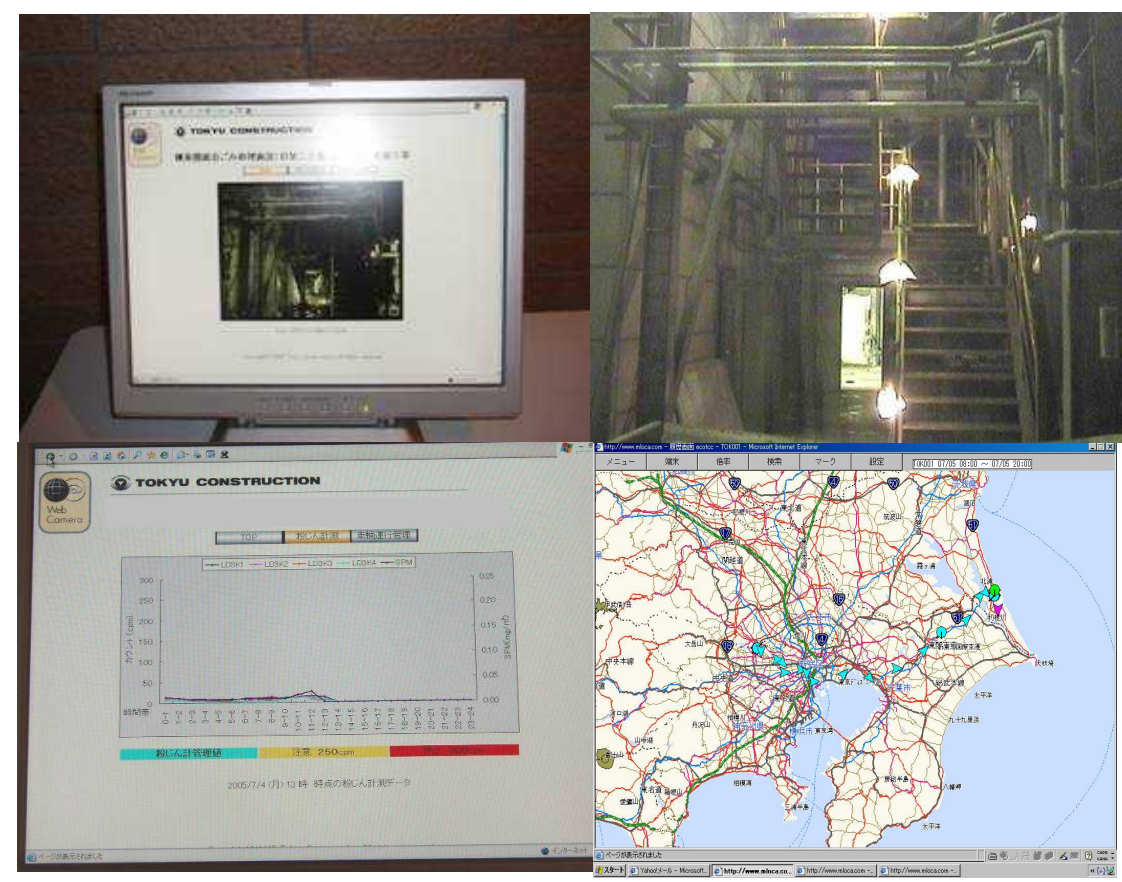

Figure 10 Video image opened to public (Upper left), Video image of demolition work (Upper right), Dust meter readings (Lower left), Position of waste carrying vehicle (Lower right) 